\title{
Genotype-Phenotype Correlation of 12S-rRNA and 16S-rRNA Variants with CPEO Plus is Unproven
}

\author{
Josef Finsterer, MD, PhD ${ }^{1}$, Sinda Zarrouk-Mahjoub, PhD $^{2}$ \\ ${ }^{1}$ Krankenanstalt Rudolfstiftung, Vienna, Austria \\ ${ }^{2}$ University of Tunis El Manar and Genomics Platform, Pasteur Institute of Tunis, Tunisia. \\ fipaps@yahoo.de \\ Corresponding Author: Finsterer J, MD, PhD, Krankenanstalt Rudolfstiftung, Vienna, Austria, Europe.
}

Key words: mitochondrial, mtDNA, phenotype, genotype, heteroplasmy rate, pathogenicity,

\section{LETTER TO THE EDITOR}

In a recent article, Lv et al. report a 48yo Han Chinese female with CPEO plus ptosis, cataract, cerebellar atrophy, and cerebral atrophy due to one mutation each in the 12S-rRNA and the 16S-rRNA respectively [1]. We have the following comments and concerns.

The main shortcoming of the report is that the patient had two different mtDNA mutations but it is neither discussed to which degree either of the two contributed to the phenotype or if both were pathogenic. Pathogenicity of the mutations is particularly questionable since the mutations did not segregate with the phenotype within the family, since no heteroplasmy rates were provided, since no biochemical investigations of the muscle homogenate had been carried out, since no single fiber studies were conducted, and since no cybrid studies had been undertaken [2fimerrf]. Given the weak evidence for the two variants to have been pathogenic, mutations in other mtDNA located genes or in nuclear gens should have been excluded.

Missing in this study is the heteroplasmy rate of either variants. It could have been determined in mtDNA from hair follicles, buccal mucosa, skin fibroblasts, blood lymphocytes, muscle, or urinary epithelial cells. Heteroplasmy rates are of paramount importance to assess the pathogenicity of either variants and to assess the degree of genotype phenotype correlation [3poulton]. Heteroplasmy rate may vary between tissues and may explain the phenotypic heterogeneity within a family.

Wealsodisagreewith the classification of thephenotype as "CPEO plus". Patients with a mitochondrial disorder (MID) frequently manifest as a multisystem disease, either already at onset of the disease or during the further course of the disease. Additionally, the phenotypic heterogeneity with and between families is broad for most of the mitochondrial mutations. Thus, most of the unsharply defined specific mitochondrial syndromes, tagged with one of the $>50$ acronyms, can present with variable plus or minus variants and may overlap considerably. For this reason it is more convenient to talk about mitochondrial multiorgan disorder syndromes (MIMODS) [4fimimodscore] and to precisely describe their highly variable phenotype.

A further shortcoming is that the patient was not sufficiently and prospectively investigated for multisystem disease. Recording of an ECG is not sufficient to exclude or confirm cardiac involvement in the MID. It is essential that MID patients undergo clinical cardiologic investigations, echocardiography and long-term ECG recordings [5wahbi15]. Since MID patients frequently present with thyroid dysfunction, diabetes, hypocorticism, hypogonadism, or hypopituitarism, such endocrine abnormalities need to be excluded or confirmed. How was subclinical or mildly manifesting gastrointestinal, renal, dermal, hematological, or pulmonary involvement excluded? Not even the height of the patient is reported.

A strong limitation of the study is that neither the mother nor the children of the index case were sufficiently investigated with regard to transmission and segregation of the mutations. .

Overall, this interesting case report could be more meaningful, if the pathogenicity of either variants would have been more strongly confirmed, if heteroplasmy rates of either variants would have been provided, if the patient would have been prospectively investigated for involvement of organs other than the brain and the eyes, and if first degree relative would have been genetically tested. 
Author's Contribution: JF: design, literature search, discussion, first draft, SZ-M: literature search, discussion, critical comments

\section{REFERENCES}

[1] Lv ZY, Xu XM, Cao XF, Wang Q, Sun DF, Tian WJ, Yang Y, Wang YZ, Hao YL. Mitochondrial mutations in 12S rRNA and 16S rRNA presenting as chronic progressiveexternalophthalmoplegia(CPEO)plus: A case report. Medicine (Baltimore) 2017 Dec; 96(48): e8869. doi: 10.1097/MD.0000000000008869.

[2] Finsterer J, Zarrouk-Mahjoub S, Shoffner JM. MERRF Classification: Implications for Diagnosis, and Clinical Trials. Pediatr Neurol 2018;(in press)
[3] Poulton J, Finsterer J, Yu-Wai-Man P. Genetic Counselling for Maternally Inherited Mitochondrial Disorders. Mol Diagn Ther 2017;21:419-429.

[4] Finsterer J, Zarrouk-Mahjoub S. Mitochondrial multiorgan disorder syndrome scoregenerated from definite mitochondrial disorders. Neuropsychiatr Dis Treat 2017;13:2569-2579.

[5] Wahbi K, Bougouin W, Béhin A, Stojkovic T, Bécane HM, Jardel C, Berber N, Mochel F, Lombès A, Eymard B, Duboc D, Laforêt P. Long-term cardiac prognosis and risk stratification in 260 adults presenting with mitochondrial diseases. Eur Heart J 2015;36:2886-93.

Citation: Josef Finsterer, MD, PhD, Sinda Zarrouk-Mahjoub, PhD. Genotype-Phenotype Correlation of 12S-rRNA and 16S-rRNA Variants with CPEO Plus is Unproven. Open Access Journal of Internal Medicine. 2018; 1(1): 5-6.

Copyright: (C) 2018 Josef Finsterer, MD, PhD, Sinda Zarrouk-Mahjoub, PhD. This is an open access article distributed under the Creative Commons Attribution License, which permits unrestricted use, distribution, and reproduction in any medium, provided the original work is properly cited. 